\title{
Influence of Nano-Spray Dried Sodium Chloride on the Physicochemical Characteristics of Surface-Salted Cheese Crackers
}

\author{
Marvin L. Moncada1, Carlos E. Astete², Cristina M. Sabliov², Douglas W. Olson', \\ Charles A. Boeneke ${ }^{1}$, Kayanush J. Aryana ${ }^{{ }^{*}}$ \\ ${ }^{1}$ School of Nutrition and Food Sciences, Louisiana State University Agricultural Center, Baton Rouge, LA, USA \\ ${ }^{2}$ Department of Biological and Agricultural Engineering, Louisiana State University Agricultural Center, Baton Rouge, LA, USA \\ Email: *karyana@agcenter.lsu.edu
}

How to cite this paper: Moncada, M.L., Astete, C.E., Sabliov, C.M., Olson, D.W., Boeneke, C.A. and Aryana, K.J. (2017) Influence of Nano-Spray Dried Sodium Chloride on the Physicochemical Characteristics of Surface-Salted Cheese Crackers. Food and Nutrition Sciences, 8, 267-276. https://doi.org/10.4236/fns.2017.82017

Received: January 21, 2017

Accepted: February 21, 2017

Published: February 24, 2017

Copyright (c) 2017 by authors and Scientific Research Publishing Inc. This work is licensed under the Creative Commons Attribution International License (CC BY 4.0).

http://creativecommons.org/licenses/by/4.0/

cC) $\underset{\mathrm{EY}}{\text { (i) Open Access }}$

\begin{abstract}
Particle size reduction of salt to submicron range increases its surface area resulting in increased saltiness perception. The objective was to evaluate the incorporation of nano-spray dried sodium chloride on the physicochemical characteristics of surface-salted cheese crackers. The sodium chloride solution (3\% w/w) was sprayed through a $4-\mu \mathrm{m}$ nozzle with $125 \mathrm{~L} / \mathrm{min}$ air flow, $38 \mathrm{kPa}$ pressure, $95^{\circ} \mathrm{C}$ head temperature, and $90 \%$ spray to form the smallest submicrosalt particles. The cheese cracker treatments consisted of 3 different salt sizes (regular, microsalt and nano-spray dried salt) and 3 different concentrations $(2 \%, 1.5 \%$ and $1 \%)$. The 9 ( 3 sizes $\times 3$ concentrations) cheese cracker treatments were tested for salt concentration and sodium content at week 1 . Water activity $\left(a_{w}\right)$, texture-fracturability, and color were determined at week 1 and 4 months of storage. The $a_{w}$ and the $L^{*}, b^{*}, C^{*}$ and $h^{*}$ values in all treatments increased from 1 week to 4 months. The use of nano-spray dried salt on surface-salted cheese crackers allowed for a reduction of $25 \%$ $50 \%$ of salt content without affecting the physicochemical attributes.
\end{abstract}

\section{Keywords}

Nano-Spray Drying, Salt, Colour, Texture, Water Activity

\section{Introduction}

Salt $(\mathrm{NaCl})$ is important from both a healthy and sensory standpoint. It is necessary for normal physiological function [1]. Saltiness is one of the five basic taste sensations (sweet, salty, sour, bitter, and umami). Humans and all animals possess an inherent appetite for salt [2]. High intakes of processed foods, such as 
prepared meals, pizza, and savory snacks, have resulted in an excessive consumption of dietary salt [3], leading to health problems including hypertension and increased risk for heart disease and stroke [4]. However, salt reduction can lead to changes in the physicochemical characteristics of food and sensory attributes. Therefore, research and development activities have been performed to reduce the salt content of foods without adversely affecting the sensory and physicochemical properties of the food.

Food color can be considered the most important product-intrinsic sensory attribute governing the sensory and hedonic expectations that influences consumer buying decision and affects their perception of the freshness of the product. Therefore, color is often measured, usually by using $L^{*}$ on a scale from 0 (absolute blackness) to 100 (representing a perfect reflecting diffuser (absolute whiteness)), $a^{*}$ (positive values indicating degree of redness and negative values indicating degree of greenness) and $b^{*}$ (positive values representing extent of yellowness and negative values representing extent of blueness).

The presence of salt reduces the $a_{w}$ in foods, meaning that there is less water available for hydration of materials [5]. Foods with high $a_{w}$ have a texture that is described as moist, juicy, tender, and chewy. Low $a_{w}$ products normally have texture attributes described as crisp and crunchy (chips and crackers) [5].

Malovany [6] reported that cheese cracker sales in the United States for 2012 were $\$ 817.1$ million and they are among the most popular snack products in North America. To reduce the sodium content of cheese crackers, Moncada et al. [7] manufactured cheese crackers that incorporated nano-spray dried salt. It was shown that these cheese crackers with nano-spray dried salt incorporated on their surfaces that resulted in a $25 \%$ and $50 \%$ reduction in salt content were accepted by consumers. These salt nanoparticles were observed by scanning electron micrographs, and $80 \%$ of these salt particles were between 500 to $1900 \mathrm{~nm}$ when analyzed by laser diffraction particle size analysis. It is not known whether $25 \%$ and $50 \%$ reduction in salt, applied in the form of nanoparticles instead of normal-sized salt particles, would alter $a_{w}$, texture-fracturability and color of surface-salted cheese crackers. The objective of this present study was to evaluate the effect of incorporation of nano-spray dried salt on surfaces of cheese crackers on the resulting physicochemical characteristics $\left(a_{w}\right.$, texture-fracturability, and color) of these crackers.

\section{Material and Methods}

\subsection{Experimental Design}

The sodium chloride nano-spray dried particles were used in the sodium reduced cheese cracker treatments. The treatments consisted of 3 different salt sizes (regular, microsalt and nano-spray dried salt) and 3 different concentrations $(2 \%, 1.5 \%$ and $1 \%)$. The 9 treatments ( 3 sizes $\times 3$ concentrations) were tested for salt concentration and sodium content at week 1 and $a_{w}$, texture-fracturability, and color at week 1 and 4 months of storage. The experimental design for $a_{w}$ texture-fracturability, and color was a CRD with repeated measures. 


\subsection{Manufacture of Nano-Spray Dried Sodium Chloride Particles}

A solution of salt in deionized water $(3 \% \mathrm{w} / \mathrm{w})$ was prepared, completely dissolved and filtered through Whatman Number 2 filter paper (Clifton, NJ, USA) and subsequently was processed by nano-spray drying (Nanospray dryer B-90, BÜCHI Labortechnik AG, Flawil, Switzerland). The sodium chloride solutions were sprayed through the $4 \mu \mathrm{m}$ nozzle. The air flow (125 l/min), pressure $(3.8$ $\mathrm{kPa})$, head temperature $\left(95^{\circ} \mathrm{C}\right)$ and spray percentage $(90 \%)$ were kept constant in all treatments.

\subsection{Cheese Cracker Manufacture}

The cheese cracker production, salt addition and packaging were performed according to Moncada et al. [7]. Briefly, the dough was rolled into sheets of $3 \mathrm{~mm}$ thickness and then trimmed into $25.4 \mathrm{~mm}$ rectangles, and a hole was incorporated at the center of each rectangle for release of water vapor to prevent puffing during baking. Baking was conducted at $177^{\circ} \mathrm{C}$ for $25 \mathrm{~min}$. The surface was very lightly sprayed with fine droplets of Canola oil. Crackers were weighed, salted at $1 \%, 1.5 \%$ and $2 \%$ by weight to the surface, and subsequently packaged in modified atmosphere packaging using $\mathrm{KOCH}$ UltraVac (Kansas City, MO, USA) packaging machine and BOPPT/VMCPP-Biaxially-Oriented PolypropylenePlastics technology/Cast Polypropylene bags, (Uline, Houston, TX, USA) and stored at $22^{\circ} \mathrm{C}$ until analysis.

\subsection{Salt Concentration Determination}

The salt concentration of the cheese crackers was determined by the Mohr method [8] with slight modification; titration with silver nitrate. The cheese cracker samples were evaluated at week 1. A $25 \mathrm{~g}$ sample of cheese crackers was weighed and transferred to a $500 \mathrm{~mL}$ Erlenmeyer flask with $250 \mathrm{~mL}$ deionized water. The solution was mixed for 1 - 3 min using a magnetic stirrer and subsequently 10 $\mathrm{mL}$ of the solution were pipetted into a $250 \mathrm{~mL}$ flask with $25 \mathrm{~mL}$ of deionized water. Potassium chromate ( 7 drops) was added to the solution. The solution was then titrated with $0.1 \mathrm{~N}$ silver nitrate until the solution changed color (bright red). The percentage of salt was determined using the equation provided by Sheen and Kahler [8].

$$
\begin{gathered}
\mathrm{NaCl}=C \times 0.583 \\
C=m l \text { of silver nitrate used } \\
0.583=\text { conversion factor for } 25 \mathrm{~g} \text { of sample }
\end{gathered}
$$

\subsection{Sodium Content Determination}

Sodium content was determined by the mathematical calculation from the salt content at week 1 . The percentage of salt was multiplied by the number of grams of sample used; subsequently that result was multiplied by the sodium percentage in the $\mathrm{NaCl}$ molecule and then multiplied by $1000(\mathrm{mg} / \mathrm{g})$ to get sodium content in $\mathrm{mg} / \mathrm{g}$. 


\subsection{Water Activity $\left(a_{w}\right)$ Measurement}

The $a_{w}$ of the cheese cracker samples was determined using a Hygrolab Rotronic 3 (Rotronic, Bassersdorf, Switzerland) at week 1 and 4 months of storage. The cheese crackers were ground with a mortar and pestle and added to $75 \%$ of the volume of $14 \mathrm{~mm}$ disposable PS-14 $a_{w}$ cups. The cheese crackers were measured using the standard function of the device, which kept measuring constant values of $a_{w}$. Subsequently, for each cheese cracker sample, $a_{w}$ was determined at the point when the sample was stable in the graph available on the software HW4. All of the measurements were carried out in triplicate.

\subsection{Texture-Fracturability Analysis}

The texture-fracturability analysis was performed with a Stable Micro Systems model TA.XTPlus Texture Analyzer (Texture Technologies Corp., Hamilton, MA, USA) using an HDP/BS blade. The weight calibration was performed daily with a $2000 \mathrm{~g}$ weight standard and the height calibration was set at $15 \mathrm{~mm}$. The set up used in the texture profile analysis (TPA) included: pretest speed of 1 $\mathrm{mm} / \mathrm{s}$, test speed of $5 \mathrm{~mm} / \mathrm{s}$ and posttest speed of $2 \mathrm{~mm} / \mathrm{s}$, the trigger system using "force", and defining $2.4 \mathrm{~mm}$ of distance.

The cheese cracker samples had a uniform surface. On the day of the analysis, the samples were removed from the modified atmosphere packaging sealed bag. Five samples from each treatment were analyzed. Fracturability (g) was evaluated.

\subsection{Color Analysis}

Evaluation of color was performed on a group of cheese cracker surfaces at 1 week and 4 months of room temperature storage, using a HunterLab MiniScan XE Plus, portable color spectrophotometer (Hunter Associates Laboratory Inc., Reston, VA, USA). The instrument was calibrated using the black and white standard tiles that came with the instrument. The operating conditions were $10^{\circ}$ observer, D65 illuminant and 45/0 sensor. An average of five values was taken per sample. An optical aperture of $1.7 \mathrm{~cm}$ was used. $L^{*}, a^{*}, b^{*}, C^{*}$ and $h^{*}$ values were recorded. Mean $L^{*}, a^{*}$, and $b^{*}$ values at each time point that was measured were used to calculate the magnitude of the total color difference $(\Delta E)$ using the equation

$$
\Delta E^{*}=\sqrt{\left(\Delta L^{*}\right)^{2}+\left(\Delta a^{*}\right)^{2}+\left(\Delta b^{*}\right)^{2}}[9] .
$$

\subsection{Statistical Analysis}

The cheese cracker data from the physical and chemical analysis were analyzed using Proc Mixed of Statistical Analysis System (SAS ${ }^{\oplus}$, Cary, NC, USA). Differences of least square means were used to determine significant differences at $P<$ 0.05 for main effects (treatment and time) and their interaction effects (treatment ${ }^{*}$ time). Significant differences were determined at $\alpha=0.05$. Significant differences $(P<0.05)$ among the main effects were analyzed using Tukey's ad- 
justment and Macro program to determine differences between treatments.

\section{Results and Discussion}

\subsection{Salt and Sodium Contents}

The salt and sodium contents of surface-salted cheese crackers as influenced by different salt particle sizes/concentrations are presented in Table 1 . These analyses confirmed that the salt usage levels of $2 \%, 1.5 \%$ and $1 \%$ were precise. Nurul et al. [10] found sodium contents of fish cracker samples were in the range of $1184-1888 \mathrm{mg} / 100 \mathrm{~g}$. This sodium in fish crackers was the result of the addition of salt and monosodium glutamate during the manufacturing process.

\subsection{Water Activity $\left(a_{w}\right)$}

The $a_{w}$ of surface-salted cheese crackers as influenced by different salt particle sizes/concentrations is shown in Table 2 . There was a significant $(P<0.05)$ effect for treatment ${ }^{*}$ time interaction, treatment and time (Table 3). The $a_{w}$ for all treatments significantly $(P<0.05)$ increased from 1 week to 4 months (Table 2). Similar results for $a_{w}$ were reported for crackers analyzed every month for 4 months by Hozova et al. [11], in which the $a_{w}$ increased from 0.16 at day 1 to

Table 1. Least square means for salt and sodium contents of surface-salted cheese cracker as influenced by treatment.

\begin{tabular}{ccc}
\hline \multirow{2}{*}{ EFFECT } & Salt Content (\%) & Sodium Content $(\mathbf{m g} / \mathbf{3 0 ~ g )}$ \\
\cline { 2 - 3 } & 1 Week & 1 Week \\
\hline Regular 2\% & 2.00 & 240 \\
Regular 1.5\% & 1.50 & 180 \\
Regular 1\% & 1.01 & 121.2 \\
Microsalt 2\% & 2.02 & 242.4 \\
Microsalt 1.5\% & 1.52 & 182.4 \\
Microsalt 1\% & 1.03 & 123.6 \\
Nano spray dried salt 2\% & 2.02 & 242.4 \\
Nano spray dried salt 1.5\% & 1.52 & 182.4 \\
Nano spray dried salt 1\% & 1.03 & 123.6 \\
\hline
\end{tabular}

Table 2. Least square means for water activity $\left(a_{w}\right)$, texture-fracturability and color of surface-salted cheese cracker at 1 week and 4 months of storage.

\begin{tabular}{|c|c|c|c|c|c|c|c|c|c|c|c|c|c|}
\hline \multirow{2}{*}{ EFFECT } & \multirow{2}{*}{$\frac{a_{w}}{1 \mathrm{Wk} 4 \mathrm{Mo}}$} & \multicolumn{2}{|c|}{ Texture-Fracturability } & \multicolumn{2}{|c|}{$L^{*}$} & \multicolumn{2}{|c|}{$a^{*}$} & \multicolumn{2}{|c|}{$b^{*}$} & \multicolumn{2}{|c|}{$C^{*}$} & \multicolumn{2}{|c|}{$h^{*}$} \\
\hline & & $1 \mathrm{Wk}$ & 4 Mo & $1 \mathrm{Wk}$ & 4 Mo & $1 \mathrm{Wk}$ & 4 Mo & $1 \mathrm{Wk}$ & 4 Mo & $1 \mathrm{Wk}$ & 4 Mo & $1 \mathrm{Wk}$ & 4 Mo \\
\hline Regular $2 \%$ & $0.15^{\mathrm{h}} 0.32^{\mathrm{b}}$ & $1306.3^{\mathrm{bcd}}$ & $1214.5^{\mathrm{bcd}}$ & $33.19^{\mathrm{hi}}$ & $52.09^{\mathrm{ab}}$ & $10.43^{\text {efgh }}$ & $13.66^{\mathrm{a}}$ & $17.02^{f}$ & $30.91^{\mathrm{a}}$ & $22.58^{\text {hi }}$ & $33.64^{\mathrm{a}}$ & $62.49^{\mathrm{d}}$ & $67.02^{\mathrm{ab}}$ \\
\hline Regular $1.5 \%$ & $0.17^{\mathrm{h}} 0.29^{\mathrm{de}}$ & $938.8^{\text {cde }}$ & $1210.0^{\mathrm{bcd}}$ & $33.09^{\mathrm{i}}$ & $43.20^{\mathrm{cd}}$ & $10.29^{\text {fgh }}$ & $11.64^{\mathrm{cd}}$ & $19.84^{\mathrm{ef}}$ & $28.01^{\mathrm{abc}}$ & $22.46^{\mathrm{i}}$ & $30.60^{\mathrm{cd}}$ & $62.74^{\mathrm{d}}$ & $67.88^{\mathrm{a}}$ \\
\hline Regular 1\% & $0.16^{\mathrm{h}} 0.33^{\mathrm{ab}}$ & $2062.5^{\mathrm{a}}$ & $1273.3^{\mathrm{bcd}}$ & $34.06^{\mathrm{ghi}}$ & $40.92^{\mathrm{d}}$ & $10.10^{\mathrm{fgh}}$ & $11.34^{\text {cde }}$ & $20.75^{\mathrm{ef}}$ & $27.54^{\mathrm{abc}}$ & $22.79^{\mathrm{ghi}}$ & $29.99^{\mathrm{de}}$ & $64.00^{\mathrm{cd}}$ & $68.04^{\mathrm{a}}$ \\
\hline Microsalt $2 \%$ & $0.18^{\mathrm{g}} 0.34^{\mathrm{a}}$ & $1291.3^{\mathrm{bcd}}$ & $986.1^{\text {cde }}$ & $37.30^{\mathrm{ef}}$ & $50.02^{\mathrm{b}}$ & $9.97^{\text {gh }}$ & $11.94^{\mathrm{bc}}$ & $21.07^{\mathrm{ef}}$ & $29.53^{\mathrm{abc}}$ & $23.34^{\text {ghi }}$ & $31.87^{\mathrm{bc}}$ & $64.76^{\mathrm{c}}$ & $67.97^{\mathrm{a}}$ \\
\hline Microsalt $1 \%$ & $0.22^{\mathrm{f}} \quad 0.34^{\mathrm{a}}$ & $1391.4^{\mathrm{bc}}$ & $1080.3^{\text {bcde }}$ & $36.77^{\mathrm{ef}}$ & $42.49^{\mathrm{d}}$ & $10.28^{\mathrm{fgh}}$ & $10.93^{\text {def }}$ & $22.00^{\mathrm{de}}$ & $26.99^{\mathrm{abc}}$ & $24.25^{\mathrm{gh}}$ & $29.11^{\mathrm{def}}$ & $65.10^{c}$ & $68.10^{\mathrm{a}}$ \\
\hline Nano-spray dried salt $2 \%$ & $0.16^{\mathrm{h}} 0.28^{\mathrm{e}}$ & $1408.9^{\mathrm{bc}}$ & $1264.7^{\mathrm{bcd}}$ & $35.43^{\text {fgh }}$ & $45.17^{c}$ & $10.53^{\text {efgh }}$ & $10.66^{\text {efgh }}$ & $21.41^{\mathrm{e}}$ & $26.35^{\mathrm{bc}}$ & $23.76^{\text {ghi }}$ & $28.46^{\mathrm{ef}}$ & $64.76^{\mathrm{c}}$ & $67.72^{\mathrm{a}}$ \\
\hline Nano-spray dried salt $1.5 \%$ & $0.21^{\mathrm{f}} 0.28^{\mathrm{e}}$ & $1255.4^{\mathrm{bcd}}$ & $879.8^{\text {de }}$ & $38.29^{\mathrm{e}}$ & $53.26^{\mathrm{a}}$ & $10.27^{\mathrm{fgh}}$ & $10.71^{\mathrm{efgh}}$ & $22.12^{\text {de }}$ & $25.81^{\mathrm{bc}}$ & $24.40^{\mathrm{g}}$ & $28.02^{\mathrm{f}}$ & $65.14^{\mathrm{c}}$ & $67.37^{\mathrm{a}}$ \\
\hline Nano-spray dried salt $1 \%$ & $0.22^{\mathrm{f}} 0.30^{\mathrm{cd}}$ & $1572.9^{\mathrm{ab}}$ & $1151.4^{\text {bcde }}$ & $33.83^{\text {ghi }}$ & $41.92^{\mathrm{d}}$ & $9.93^{\mathrm{h}}$ & $10.84^{\mathrm{defg}}$ & $20.34^{\mathrm{ef}}$ & $26.36^{\mathrm{bc}}$ & $22.70^{\mathrm{hi}}$ & $28.49^{\mathrm{ef}}$ & $63.59^{\mathrm{d}}$ & $67.79^{\mathrm{a}}$ \\
\hline
\end{tabular}

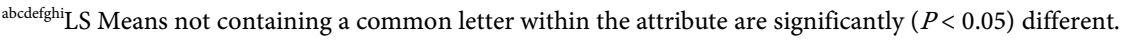


Table 3. Probability $>$ F of different particle size treatments, time and their interaction for the water activity $\left(a_{w}\right)$, texture-fracturability, and color attributes of surface-salted cheese crackers.

\begin{tabular}{|c|c|c|c|c|c|c|c|}
\hline \multirow{2}{*}{ EFFECT } & $a_{w}$ & Texture-fracturability & $L^{*}$ & $a^{*}$ & $b^{*}$ & $C^{*}$ & $h^{*}$ \\
\hline & $\operatorname{Pr}>F$ & $\operatorname{Pr}>\mathrm{F}$ & $\operatorname{Pr}>F$ & $\operatorname{Pr}>F$ & $\operatorname{Pr}>F$ & $\operatorname{Pr}>F$ & $\operatorname{Pr}>\mathrm{F}$ \\
\hline TRT & $<0.001$ & $<0.001$ & $<0.001$ & $<0.001$ & $<0.001$ & $<0.001$ & $<0.001$ \\
\hline TIME & $<0.001$ & $<0.001$ & $<0.001$ & $<0.001$ & 0.033 & $<0.001$ & $<0.001$ \\
\hline TRT*TIME & $<0.001$ & $<0.001$ & $<0.001$ & $<0.001$ & $<0.001$ & $<0.001$ & $<0.001$ \\
\hline
\end{tabular}

0.34 at the end of storage (4 months). Crackers containing 2\%, $1.5 \%$ and $1 \%$ nano-spray dried salt had significantly $(P<0.05)$ lower $a_{w}$ than crackers containing $2 \%$ microsalt and $2 \%$ regular salt at 4 months (Table 2). Also, crackers containing $1 \%$ nano-spray dried salt had significantly lower $a_{w}$ than crackers containing $1 \%$ microsalt and $1 \%$ regular salt at 4 months (Table 2). Additionally, the $a_{w}$ results found in this study did not reach the limit of 0.5 , which would be required for the growth of yeast that could adversely affect the sensory characteristics. The $a_{w}$ of the cheese crackers (ranging from 0.15 to 0.22 at 1 week and from 0.28 to 0.34 at 4 months) was less than the external percent relative humidity in Louisiana $(75 \%-85 \%)$ as observed by Weather Underground [12]. Some moisture may have permeated into the package, increasing the $a_{w}$ of the cracker. The rate of gain or loss of moisture is a function of film permeability and the surface area to volume (solid weight) ratio of the contained food [13]. However, the package used had low oxygen permeability $\left(0.9 \mathrm{ml} / \mathrm{m}^{2} \cdot\right.$ day $)$ (metalized polyester and polyethylene bonded film) [14]. Additionally, Adams and Moss [15] concluded that salt, when it is ionized completely into sodium and chloride ions in water, makes the water unavailable for microbial growth due to the ion hydration, and therefore, is more effective at reducing the $a_{w}$ of food than other ingredients like sucrose.

\subsection{Texture Fracturability}

The texture fracturability analysis of surface-salted cheese crackers as influenced by different salt particle sizes/concentrations is shown in Table 2 . There was a significant $(P<0.001)$ effect for treatment ${ }^{*}$ time interaction, treatment and time (Table 3). Crackers containing $1.5 \%$ microsalt and $1 \%$ regular salt significantly $(P<0.05)$ decreased in fracturability from 1 week to 4 months (Table 2). Also, crackers containing $1.5 \%$ microsalt had significantly $(P<0.05)$ lower fracturability than crackers containing $1.5 \%$ regular salt at 4 months (Table 2 ). The reduction of $25 \%(1.5 \%)$ and $50 \%(1 \%)$ of salt content in surface-salted cheese crackers through use of nano-spray dried salt did not show significant differences in texture fracturability. Nakamura et al. [16] studied the quality deterioration of rice crackers over time using the one bite test with tensipresser and concluded that the hardness of cracker markedly increased during storage of 20 days at $35^{\circ} \mathrm{C}$. Its changes were attributed to the retrogradation of rice starch over time. In this study we did not use rice starch. 


\subsection{Color}

\subsection{1. $L^{*}$}

The $L^{*}$ (lightness) of surface-salted cheese crackers as influenced by different salt particle sizes/concentrations is shown in Table 2. There was a significant $(P<0.001)$ effect for treatment ${ }^{*}$ time interaction, treatment and time (Table 3). $L^{*}$ values of crackers in all treatments increased significantly $(P<$ 0.05 ) from 1 week to 4 months (Table 2). This increase in lightness was attributed to the effect of ingredients (cayenne pepper and cheese) in the cheese cracker. The dried red pepper (cayenne pepper) powder loses a part of its pigments (capsorubin, capsanthin, zeaxanthin, lutein and $\beta$-carotene) during storage, which is attributed to the time and temperature of storage, oxygen in air, light, moisture content of the product and type of packaging [17]. At 1 week and 4 months, crackers containing $1.5 \%$ nano-spray dried salt was significantly $(P<0.05)$ lighter than crackers containing $1.5 \%$ regular salt (Table 2$)$. At 4 months, crackers containing $2 \%$ nano-spray dried salt was significantly $(P<$ $0.05)$ darker than crackers containing $2 \%$ microsalt and $2 \%$ regular salt, and there were no significant differences $(P>0.05)$ in lightness of crackers between the $1 \%$ treatments (Table 2).

Different factors affect lightness of foods. Mohamed et al. [18] concluded that the type of flour used affected the clarity (color) of the fish crackers. Another factor that could have affected the color of fish crackers was the Maillard reaction, resulting from sugar in the formulation. This reaction occurs between the free amino group of lysine and other amino acids and the carbonyl groups of reducing sugars such as glucose, fructose, lactose and maltose [19]. Additionally, Camire et al. [19] reported that the Maillard reaction occurs during high temperatures and low moisture conditions used during industrial treatments of foods.

Hempel et al. [20] evaluated wafer crackers made with ultrafiltered syrup and different types of flour and found that the color of the crackers was lighter than without use of ultrafiltered syrup. They evidently attributed the results to the reduction (isomerization) of reducing sugar monomers in the syrup. Opposite results were found by Nurul et al. [10] who evaluated the effect of different ratios of fish meat to tapioca flour in fish cracker and found a decrease in lightness $\left(L^{*}\right)$ with an increase in the ratio of fish meat to tapioca flour. In our study, the protein source was not fish meat, but cheese and wheat flour.

\subsection{2. $a^{*}$}

The $a^{*}$ of surface-salted cheese crackers as influenced by different salt particle sizes/concentrations is shown in Table 2 . There was a significant $(P<0.001)$ effect for treatment * time interaction, treatment and time (Table 3). At 4 months, crackers subjected to $2 \%$ and $1.5 \%$ nano-spray dried salt treatments had significantly $(P<0.05)$ lower $a^{*}$ values than crackers containing the $2 \%$ and $1.5 \%$ regular salt (Table 2). Nurul et al. [10] reported that the redness $\left(a^{*}\right)$ of fish crackers tended to decrease with an increase in the ratio of fish meat to tapioca flour. Malchev et al. [17] concluded that the red component of the pigment 
complex degraded faster than the yellow component. Additionally, the capsorubin, capsanthin, zeaxanthin, $\beta$ lutein and $\beta$ - and $\alpha$-carotene were more stable in the dried red pepper than in the red pepper powder during 6 months of storage. In our study, similar changes in reddish color were found from 1 week to 4 months, which could be attributed to the pigment degradation of the cayenne pepper used in the cheese cracker formulation.

\subsection{3. $b^{*}$}

The $b^{*}$ of surface-salted cheese crackers as influenced by different salt particle sizes/concentrations is shown in Table 2 . There was a significant $(P<0.05)$ effect for treatment ${ }^{*}$ time interaction, treatment and time (Table 3). The $b^{*}$ values for all treatments of the cheese crackers increased significantly $(P<0.05)$ from 1 week to 4 months (Table 2). This increase in yellowness was attributed to the effect of ingredients in the cheese cracker. At 4 months, cheese crackers containing $2 \%, 1.5 \%$ and $1 \%$ nano-spray dried salt had significantly $(P<0.05)$ lower $b^{*}$ values than cheese crackers containing $2 \%$ regular salt (Table 2). Riboflavin and carotenoids contribute to the yellowish color of cheese, and the degradation of these compounds during light exposure may result in discoloration of the product [21]. Similar changes in yellowish color were found in our study; it could be attributed to the amount of cheese (61\%) used in the cracker formula. Nurul et al. [10] reported that yellowness $\left(b^{*}\right)$ tended to be higher in samples with low amounts of fish meat. Additionally, Kristensen et al. [22] reported that the havarti cheese packaged in modified atmosphere packaging $\left(25 \% \mathrm{CO}_{2}\right.$ and $75 \% \mathrm{~N}_{2}$ ) and exposed to light significantly decreased in yellowness values when stored for up to $21 \mathrm{~d}$ at $51^{\circ} \mathrm{C}$.

\subsection{4. $C^{*}$}

The $C^{*}$ (chroma/saturation) of surface-salted cheese crackers as influenced by different salt particle sizes/concentrations is shown in Table 2. There was a significant $(P<0.001)$ effect for treatment ${ }^{*}$ time interaction, treatment and time (Table 3). The $C^{*}$ values for all treatments of the cheese crackers increased significantly $(P<0.05)$ from 1 week to 4 months (Table 2$)$. This increase in $C^{*}$ values was attributed to the ingredient effects/changes in the cheese cracker. At 1 week, cheese crackers containing $1.5 \%$ nano-spray dried salt had significantly $(P<$ 0.05 ) higher $C^{*}$ values than cheese crackers containing $1.5 \%$ and $2 \%$ regular salt (Table 2). At 4 months, cheese crackers subjected to $2 \%, 1.5 \%$ and $1 \%$ nano-spray dried salt treatments had significantly $(P<0.05)$ lower $C^{*}$ values than cheese crackers containing $2 \%$ and $1.5 \%$ regular salt (Table 2). Hempel et al. [20] concluded that the wafer crackers made with ultrafiltered syrup were less saturated than crackers made without ultrafiltered syrup. They attributed this effect in $C^{*}$ to the reduction (isomerization) of reducing sugar monomers in the syrup, therefore resulting in extensive non-enzymatic browning changes.

\subsection{5. $h *$}

The $h^{*}$ (hue) of surface-salted cheese crackers as influenced by different salt 
particle sizes/concentrations is shown in Table 2. There was a significant $(P<$ $0.001)$ effect for treatment ${ }^{*}$ time interaction, treatment and time (Table 3 ). The $h^{*}$ values for all treatments of the cheese crackers increased significantly $(P<$ 0.05 ) from 1 week to 4 months (Table 2). This increase in hue values was attributed to the ingredient effects/changes in the cheese cracker. At 1 week, cheese crackers containing $2 \%$ and $1.5 \%$ nano-spray dried salt had significantly $(P<$ $0.05)$ higher hue values than cheese crackers containing $2 \%$ and $1.5 \%$ regular salt (Table 2). However, at 4 months there were no significant $(P>0.05)$ differences in hue values between all treatments of cheese crackers (Table 2).

\section{Conclusion}

The effect of different salt concentrations (2\%, $1.5 \%$, and $1 \%)$ and particle sizes (nano-spray dried salt, microsalt, and regular salt) at the surface of cheese crackers on physicochemical characteristics of the crackers was evaluated. The $a_{w}$ and color values for all treatments of cheese crackers increased from 1 week to 4 months. The reduction of $25 \%$ and $50 \%$ salt content in cheese crackers through use of nano-spray dried salt did not adversely influence the physicochemical attributes.

\section{Acknowledgements}

This study was funded by USDA Hatch funds and Louisiana State University Agricultural Center, Baton Rouge, LA.

\section{Conflicts of Interests}

The authors declare no conflicts of interest.

\section{References}

[1] Salt Institute (2016) Health Overview. http://www.saltinstitute.org/health/overview/

[2] Salt Institute (2016) Salt 101. http://www.saltinstitute.org/salt-101/

[3] He, J., Ogden, L.G., Vupputuri, S., Bazzano, L.A., Loria, C. and Whelton, P.K. (1999) Dietary Sodium Intake and Subsequent Risk of Cardiovascular Disease in Overweight Adults. The Journal of the American Medical Association, 282, 2027 2034. https://doi.org/10.1001/jama.282.21.2027

[4] Centers for Disease Control and Prevention (2016) Salt. http://www.cdc.gov/salt/index.htm

[5] Aqualab (2015) Water Activity for Product Safety and Quality. http://www.aqualab.com/education/water-activity-for-product-safety-and-quality/

[6] Malovany, S. (2013) State of the Industry Report: Top Cracker Brands. Snack World, 26.

[7] Moncada, M., Sabliov, C., Astete, C., Olson, D., Boeneke, C. and Aryana, K. (2015) Nano Spray-Dried Sodium Chloride and Its Effects on the Microbiological and Sensory Characteristics of Surface-Salted Cheese Crackers. Journal of Dairy Science, 98, 5946-5954. https://doi.org/10.3168/jds.2015-9658

[8] Sheen, R.T. and Kahler, H.L. (1938) Effects of Ions on Mohr Method for Chloride 
Determination. Industrial and Engineering Chemistry, Analytical Edition, 10, 628629. https://doi.org/10.1021/ac50127a004

[9] Hunter Associates Laboratory (2003) MiniScan XE Plus User’s Guide.

[10] Nurul, H., Boni, I. and Noryati, I. (2009) The Effect of Different Ratios of Dory Fish to Tapioca Flour on the Linear Expansion, Oil Absorption, Colour and Hardness of Fish Crackers. International Food Research Journal, 16, 159-165.

[11] Hozova, B., Buchtova, V., Dodok, L. and Zemanovic, J. (1997) Microbiological, Nutritional and Sensory Aspects of Stored Amaranth Biscuits and Amaranth Crackers. Nahrung, 41, 151-158.

[12] Weather Underground (2013) Baton Rouge, LA. https://www.wunderground.com/history/airport/KBTR/2013/4/22/DailyHistory.ht ml?req_city $=\&$ req_state $=\&$ req_statename $=\&$ reqdb.zip $=\&$ reqdb.magic $=\&$ reqdb.wm $\underline{\mathrm{o}}$

[13] Barbosa-Cánovas, G., Fontana, A.J. and Schmidt, S. (2008) Water Activity in Foods: Fundamentals and Applications. IFT Series, Vol. 13, John Wiley \& Sons, Hoboken. http://books.google.com/books

[14] Uline (2013) Packaging Materials. http://www.uline.com

[15] Adams, M. and Moss, M. (2000) Food Microbiology. 2nd Edition, The Royal Society of Chemistry, London.

[16] Nakamura, S., Suzuki, D., Kitadume, R. and Ohtsubo, K. (2012) Quality Evaluation of Rice Crackers Based on Physicochemical Measurements. Bioscience, Biotechnology, and Biochemistry, 76, 794-804. https://doi.org/10.1271/bbb.110931

[17] Malchev, E., Loncheva, N., Tanchev, S. and Kalpakchieva, K. (1982) Quantitative Changes in Carotenoids during the Storage of Dried Red Pepper. Nahrung, 26, 415420. https://doi.org/10.1002/food.19820260503

[18] Mohamed, S., Abdullah, N. and Muthu, M.K. (1989) Physical Properties of Fried Crisps in Relation to the Amylopectin Content of the Starch Flours. Journal of the Science of Food and Agriculture, 49, 369-377. https://doi.org/10.1002/jsfa.2740490312

[19] Camire, M.E., Camire, A. and Krumhar, K. (1990) Chemical and Nutritional Changes in Foods during Extrusion. Critical Reviews in Food Science and Nutrition, 29, 35-57. https://doi.org/10.1080/10408399009527513

[20] Hempel, S., Jacob, A. and Rohn, H. (2007) Influence of Inulin Modification and Flour Type on Sensory Quality of Prebiotic Wafer Crackers. European Food Research and Technology, 224, 335-341. https://doi.org/10.1007/s00217-006-0326-9

[21] Bosset, J., Sieber, O.R. and Gallmann, P.U. (1995) Light Transmittance: Influence on the Shelf Life of Milk and Milk Products. Bulletin of the International Dairy Foundation, 300, 19-39.

[22] Kristensen, D., Orlien, V., Mortensen, G., Brockhoff, P. and Skibsted, L.H. (2000) Light-Induced Oxidation in Sliced Havarti Cheese Packaged in Modified Atmosphere. International Dairy Journal, 10, 95-103. https://doi.org/10.1016/S0958-6946(00)00028-5 
Submit or recommend next manuscript to SCIRP and we will provide best service for you:

Accepting pre-submission inquiries through Email, Facebook, LinkedIn, Twitter, etc. A wide selection of journals (inclusive of 9 subjects, more than 200 journals)

Providing 24-hour high-quality service

User-friendly online submission system

Fair and swift peer-review system

Efficient typesetting and proofreading procedure

Display of the result of downloads and visits, as well as the number of cited articles Maximum dissemination of your research work

Submit your manuscript at: http://papersubmission.scirp.org/

Or contact fns@scirp.org 